\title{
Biologically Potential for Pharmacologicals and Phytochemicals of Medicinal Plants of Colocasia esculenta: A Comprehensive Review
}

\author{
Md. Reyad-ul-Ferdous ${ }^{1,2, ~ *, ~ M d . ~ S a i f u l ~ I s l a m ~ A r m a n ³, ~ M d . ~ M u n i r u l ~ I s l a m ~ T a n v i r ~}{ }^{4}$, \\ Shamsunnahar Sumi ${ }^{2}$, Kazi Md. Mostafizur Rahman Siddique ${ }^{5}$, Md. Mustahsan Billah ${ }^{6}$, \\ Md. Siddiqul Islam ${ }^{7}$ \\ ${ }^{1}$ Department of Pharmacy, Progati Medical Institute, Dhaka, Bangladesh \\ ${ }^{2}$ Department of Pharmacy, North South University, Dhaka, Bangladesh \\ ${ }^{3}$ Department of Pharmacy, University of Rajshahi, Rajshahi, Bangladesh \\ ${ }^{4}$ Department of Pharmacy, International Islamic University Chittagong, Chittagong, Bangladesh \\ ${ }^{5}$ Department of Pharmacy, University of Asia Pacific, Dhaka, Bangladesh. \\ ${ }^{6}$ Department of Pharmacy, Noakhali Science and Technology University, Noakhali, Bangladesh \\ ${ }^{7}$ Department of Clinical Pharmacy and Pharmacology, University of Dhaka, Dhaka, Bangladesh
}

Email address:

rockyreyad@yahoo.com (Md. Reyad-ul-Ferdous)

\section{To cite this article:}

Md. Reyad-ul-Ferdous, Md. Saiful Islam Arman, Md. Munirul Islam Tanvir, Shamsunnahar Sumi, Kazi Md. Mostafizur Rahman Siddique, Md. Mustahsan Billah, Md. Siddiqul Islam. Biologically Potential for Pharmacologicals and Phytochemicals of Medicinal Plants of Colocasia esculenta: A Comprehensive Review. American Journal of Clinical and Experimental Medicine. Special Issue: Herbal Remedies as Alternative to Future Drugs Development and Treatment. Vol. 3, No. 5-1, 2015, pp. 7-11. doi: 10.11648/j.ajcem.s.2015030501.12

\begin{abstract}
Colocasia esculenta $(L)$ Schott of the family Araceae is an herbaceous perennial plant cultivated as annuals. Local name of $C$. esculenta is Kochu in Bangladesh and Taro in India. C. esculenta $(L)$ is an ancient crop grown throughout the humid tropics and is widely used throughout the world; Africa, Asia, the West Indies, and South America. Its edible corms and leaves are traditionally used for hepatic ailments. Juice obtained from stems. Schott is used to stop bleeding from cuts and Wounds. The young leaves and roots are rich in Vitamin $\mathrm{C}$ as well as starch. It contains calcium, phosphorours, thiamine, riboflavin, niacin, oxalic acid, calcium oxalate, sapotoxin and flavones, apigenin and luteolin. The biological properties as well as chemical constituents of plant $C$. esculenta were widely used in folk medicine. In traditional medicine, $C$. esculenta is used as Anti microbial, Antihepatotoxic, Anti-cancer, Anti-Lipidperoxidative, Antibacterial and Antifungal, Antidiabetic, Antimelanogenic, Anthelmintic. In present study, C. esculenta shows potent pharmacological activity such as Antimicrobial, Antihepatotoxic, Anti-cancer, Anti-Lipidperoxidative, antibacterial and Antifungal, Antidiabetic, Anti-melanogenic, Anthelmintic. Due to present of several potential chemical constituents it may use in several disease conditions for the future treatment.
\end{abstract}

Keywords: Colocasia esculenta, Phytochemicals, Pharmacologicals, Antihepatotoxic, Anti-Cancer, Antidiabetic, Anti-Lipidperoxidative, Anti-Melanogenic, Anthelmintic

\section{Introduction}

Various medicinal plants have been used for thousands years in daily life to treat disease all over the world. It was used as vital sources of medicine. The medicinal plants were anciently use of herbal remedies and healthcare preparations including Vedas and the Bible. In fact, plants contain diverse range of bioactive molecules, to make them a rich source of different types of medicines [1]. All plants, as sources of different medicinal compounds shows dominant role in the maintenance of human health since ancient times [2]. All modern clinical drugs around $50 \%$ of are of natural product origin [3] and in drug development programs in the pharmaceutical industry natural products play a significance 
role [4]. Plants can dominant synthetic drugs molecule to treat major diseases and also provide lead compound to development of potential synthetic drugs molecule [5]. Medicinal plant has relatively lower incidence of adverse reactions and can be use as alternatives to synthetic drugs [6, $7,8,9]$ as well as much work available on ethno medicinal plants in India [10]. Traditional natural products are increased now as a form of modern medicine [11]. Recent studies suggested that aqueous and ethanol extracts from plants used in allopathic medicine are potential sources of antiviral, antitumor and antimicrobial agents etc $(12,13]$. $C$. Esculenta belongs to the family Araceae and commonly known as Taro. The leaf juice of the plant is stimulant and rube facient as well as styptic. It's also useful in internal otalgia, adenitis, haemorrhages and buboes. True taros are grown in the South Pacific for hundreds of years and available in the tropical region between India and Indonesia. Leaves are also used as a vegetable. The plant is a herb, with clusters of long heart or arrow heads haped leaves that point earthwards. It contains erect stems that may be green, red black or variegated as well as few meters high. The plants consist of several phyto-chemicals such as Vitamin C, thiamine, sapotoxin, oxalic acid, calcium oxalate, niacin, and riboflavin. The tubers contain amino acids and proteins. The corms contain the cyaniding 3- rhamnoside, cyaniding 3glucoside and anthocyaninsperlargonidin 3glucoside.Traditionally it is used to treat the stomach swelling and pain and fever. It is also used to treat poultice on infected sores [14]. The large green leaves known as 'elephant ear' and 1-2 m high. The tuberous root is the main edible part of the crop. The leaf juice also used in snake bite as well as food poisoning in plant origin as traditional medicines [15].

\section{Pharmacological Activities of $C$. esculenta}

Plants are the major sources of drugs or molecule which demonstrate mild to significant pharmacological activity against tremendous organisms and diseases. Pharmacological activity and phyto-constituents demonstrate in the table- 1 and table-2.

\subsection{Anti-Microbial and Anti-Fungal Activities of C. esculenta}

C. esculenta shows the antimicrobial activity of chloroform and methanol extract by agar diffusion method. In this studies chloroform and methanol extract shows in several dose such as $20,10,5,2.5,1.25,0.625,0.3125 \mathrm{mg} / \mathrm{ml}$ against some selected strains was measured and compared with standard antibiotics tetracycline in dose of 5, 2.5, 0.625, $0.3125,0.15625,0.078072 \mathrm{mg} / \mathrm{ml}$ [16]. Aqueous extract of $C$ Esculenta was conducted in gram positive i.e Streptococcus mutans (MTCC-890), Bacillus subtillis (MTCC-121) and gram negative i.e Klebsiella pneumonia (MTCC-109), Pseudomonas fragi (MTCC-2458), Escherichia coli (MTCC-
483) as well as fungal strains Aspergillus niger (MTCC-281) Candida albicans (MTCC-227). The results exhibited good activity against tested organisms [19].

\subsection{Anti-Cancer Activity of C. esculenta}

In this study $C$. esulenta extracts was conducted in vitro for anti-proliferative activity against the rat YYT colon cancer cell line. Pio can significantly reduce colon cancer rate among Hawaiians by two distinct mechanisms. One is inducing apoptosis within colon cancer cells and second one is non-specifically activating lymphocytes which in turn can lyse cancerous cells. In this experiment results demonstrate that that poi may have novel tumor specific anti-cancer activities and future research is suggested with animal studies and human clinical trials [17].

\subsection{Anti-Eppatotoxic Activity of C. esculenta}

In this study the anti-hepatotoxic and hepatoprotective studies were carried against two well known hepaotoxins paracetamol and CCL4 using in vitro liver slice method. The liver cell was oxidized by free radicals generated factors such as CCL4 and paracetamol. C. esculenta leaf juice was measured using the leakage of marker enzymes of liver function viz AST, ALT and ALP in the incubation medium. The leaf juice of $C$. esculenta remarkably declined the leakage of AST, ALT and ALP in the medium indicating hepatocyte integrity. This investigation is support that $C$. esculenta leaf juice as a whole possesses anti-hepatotoxic and hepatoprotective efficacy when tested in vitro using rat liver slice model [15].

\subsection{Anti-Lipid Peroxidative Activity of C. esculenta Leaf Juice Against ccl4 and Acetaminophen Mediated Cell Damage}

In this experiment $C$. esculenta whole leaf juice was conducted free radical scavenging efficacy. The free radicals were generated using by the two well known hepatotoxins ccl4 and acetaminophen. The effect of free radicals was studied on liver cells by in vitro rat liver slice model. The evaluation was carried using the Thio-Barbituric Acid Reactive Substances and the total glutathione levels in the liver tissue. This results show significance free radical scavenging efficacy [18].

\subsection{Anti-Diabetic Activity of C. esculenta}

The present study suggested that ethanol extract of $C$. esculenta (EECE) leaves were subjected to anti-diabetic activity on blood glucose level and on the body weight in alloxan induced diabetic rats in doses of EECE (100, 200 and $400 \mathrm{mg} / \mathrm{kg})$ and metformin $(450 \mathrm{mg} / \mathrm{kg})$ were administered orally in alloxan $(120 \mathrm{mg} / \mathrm{kg}$, i.p.). The results demonstrate significant $(p<0.001)$ blood glucose lowering effect i.e observed reduction in blood glucose was $(174.34 \mathrm{mg} / \mathrm{dl})$ at the dose of $400 \mathrm{mg} / \mathrm{kg}$ on 14th day [20]. 


\subsection{Anti-Melanogesnic Activity of C. esculenta}

Recent data suggested that the methanolic extract of tuberbarks of Colocasia antiquorum var. Esculenta contain a new chemicals such as monoglyceride, (2'S)-1-O-(9-oxo-10(E), 12(E)-octadecadienoyl) glycerol. This compound was demonstrating significant anti-melanogenic activity [21].

\subsection{Antihelmintic Activity of C. esculenta}

Aqueous and Ethanolic extract of the leaf from $C$. esculenta were investigated for anthelmintic activity against earthworm. The results exhibited significant anthelmintic activity at highest concentrations at $50 \mathrm{mg} / \mathrm{ml}$ extract compared with standard with Piperazine citrate $(10 \mathrm{mg} / \mathrm{ml})$.

Table 1. presenting various pharmacological activities attributed to $C$. esculenta.

\begin{tabular}{ll}
\hline Activity & References \\
\hline Anti microbial & 16 \\
Anti-cancer & 17 \\
Antihepatotoxic & 15 \\
Anti- Lipidaperoxidative & 18 \\
Antibacterial and Antifungal & 19 \\
Antidiabetic & 20 \\
Anti-melanogenic & 21 \\
Anthelmintic & 14 \\
\hline
\end{tabular}

Table 2. presenting various chemical constituents of $C$. esculenta.

\begin{tabular}{lll}
\hline Chemical Compounds & Parts & References \\
\hline Vitamin C & Leaves & 16,14 \\
Starch & Root s & 16,14 \\
Amino Acid & Tubers ,Leaf & 16,14 \\
Protein & Leaves & $16,14,15$ \\
Anthocyaninsperlargonidin 3-glucoside & Corm & 16,14 \\
Cyaniding 3-glucoside & Corm & 16,14 \\
Cyaniding 3-rhamnoside & Corm & 16,14 \\
B-sitosterol & Leaves & 22 \\
Steroids & Leaves & 22 \\
Flavonoids & Leaves & 22,23 \\
Calcium & Leaves & 15,18 \\
Phosphorous & Leaves & 15,18 \\
Iron & Leaves & 15,18 \\
Vitamin C & Leaves & 15,18 \\
Thiamine & Leaves & 15,18 \\
Riboflavin & Leaves & 15,18 \\
Niacin & Leaves & 15,18 \\
Minerals & Leaves & 18 \\
Saponins & Leaves & 23 \\
Terpernes & Leaves & 23 \\
Anthraquinones & Leaves & 23 \\
Cardiac Glycosides & Leaves & 23 \\
Alkaloids & Leaves & 23 \\
Ascorbic acid & Leaves & 15 \\
\hline
\end{tabular}

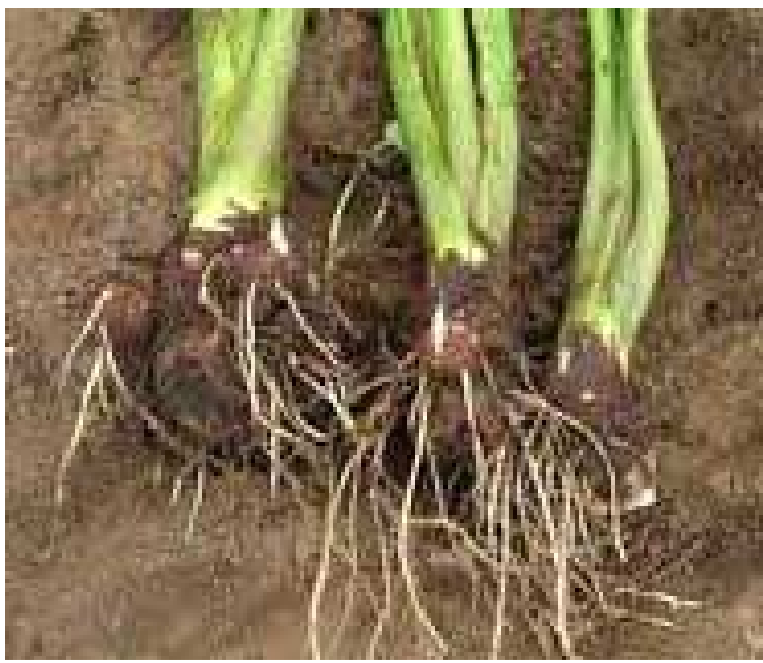

Figure a. Root of Colocasia esculenta .

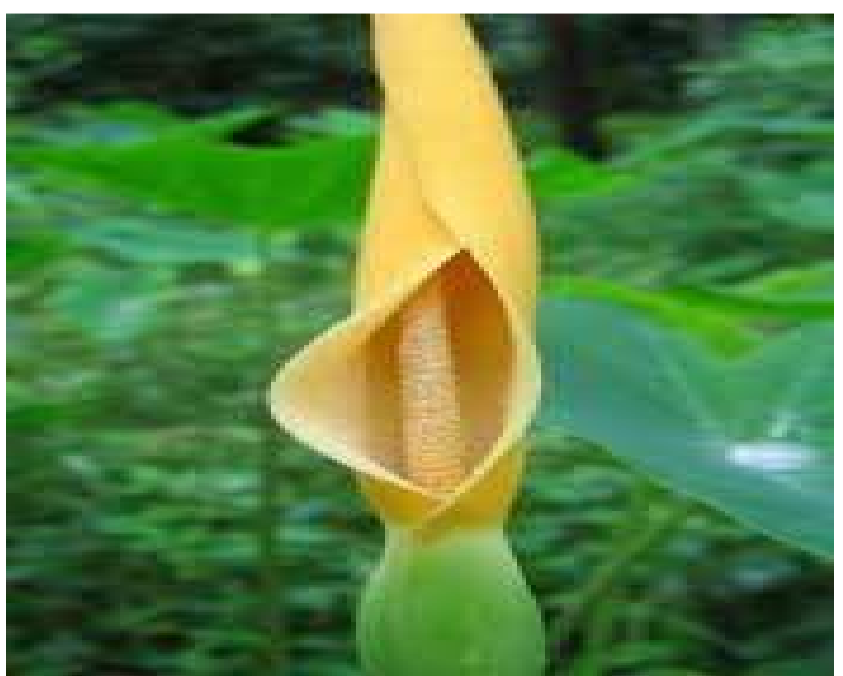

Figure b. Flower of Colocasia esculenta.

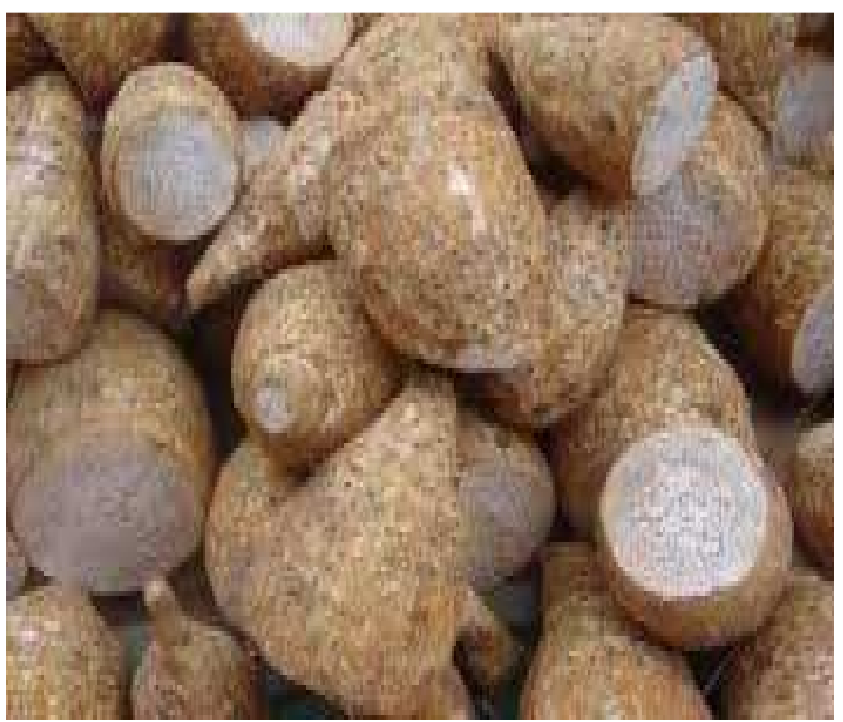

Figure c. Fruit of Colocasia esculenta. 


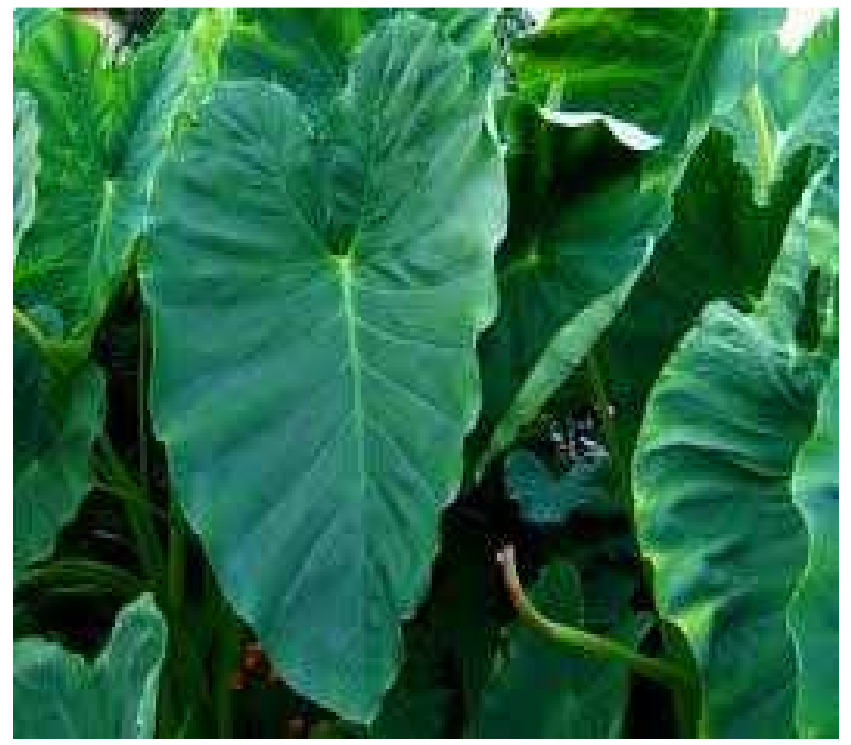

Figure d. Leaves of Colocasia esculnta.

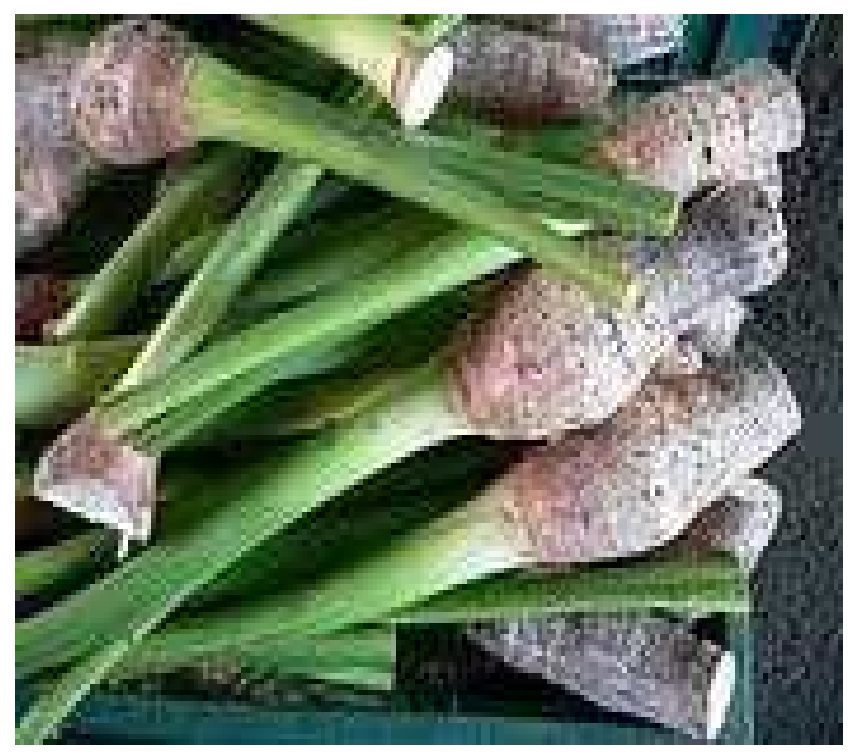

Figure e. Steam of Colocasia esculenta.

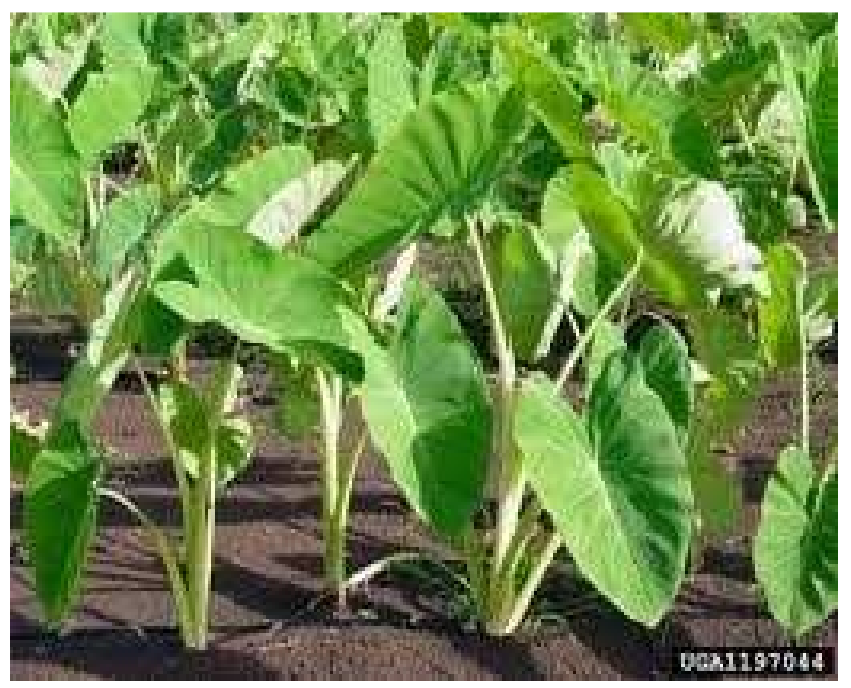

Figure $f$. Whole plant of Colocasia esculenta.

\section{References}

[1] Kala, C. P., Dhyani, P. P., Sajwan,B. S. Developing the medicinal plants sector in Northern India: Challenges and opportunities. J. Ethnobiol. Ethnomed.2, 32 (2006).

[2] Farombi, E. O. African indigenous plants with chemotherapeutic potentials and biotechnological approach to the production of bioactive sporophylactic agents. African $J$. Biotech.2 (12), 662-671 (2003).

[3] Stuffness, M., Douros, J. Current status of the NCI plant and animal product program. $J$ Nat Prod.45, 1-14 (1982).

[4] Baker, J. T., Borris, R. P., Carté, B., Cordell, G. A., Soejarto, D. D., Cragg, G. M., Gupta, M. P., Iwu, M. M., Madulid, D. R., Tyler, V. E. Natural product drug discovery and development: New perspective on international collaboration. J. Nat. Prod.58, 1325-1357 (1995).

[5] Dulger, B., Gonuz, A. Antimicrobial Activity of Certain Plants used in Turkish Traditional Medicine. Asian J. Of Plant Sciences. 3(1), 104-107 (2004).

[6] Reddy, P. S., Jamil, K., Madhusudhan, P. Antibacterial activity of isolates from Piper longumand Taxusbaccata. Pharmaceutical Biol.39 (3), 236-238 (2001).

[7] Erdogrul, O. T. Antibacterial activities of some plant extracts used in folk medicine. Pharmaceutical Biol.40 (4), 269-273 (2002).

[8] Ateb, D. A., Erdourul, O. T. Antimicrobial activities of various medicinal and commercial plant extracts. Turk. J. Biol.27, 157-162 (2003).

[9] Uysal, I., Celik, S., Oldacay, M. Antimicrobial activity of anthemiscoelopodavar. Bourgaeiboiss and anthemistinctoriavar. Pallida DC. Species having ethnobotanical features. J. Applied Sci.5 (4), 639-642 (2005).

[10] Rai, M. K.Ethnomedicinal studies of Chhindwara district (M.P.). I. Plants used in stomach disorders. Ind. Med.1, 1989, 1-5 (1989).

[11] Taylor, R. S. L., Manandhar, N. P., Hudson, J. B., Towers, G. H. N. Antiviral activities of Nepalese medicinal plants. $J$. Ethnopharmacol.52, 157-163 (1996).

[12] Chung, T. H., Kim, J. C., Kim, M. K., Choi, S. C., Kim, S. L. Investigation of korean plant extracts for potential phytotherapeutic agents against B-virus hepatitis. Phytotherapy Res. 9(6), 429-434 (1995).

[13] Vlietinck, A. J., Van Hoof, L., Tott, J. Screening of hundred Rwandese medicinal plants for antimicrobial and antiviral properties. J. Ethnopaharmacol.46, 31-47 (1995).

[14] Kubde, M. S., Khadabadi,S. S. Farooqui, I. A., Deore, S. L. In-vitro anthelmintic activity of Colocasia esculenta. Der Pharmacia Lettre. 2(2), 82-85 (2010).

[15] Patil, B. R., Ageely, H. M.Anti hepatotoxic activity ofcolocasiaesculenta leaf juice. International Journal of Advanced Biotechnology and Research. 2(2), 296-304 (2011).

[16] Kubde, M. S.,Khadabadi, S. S.,Saboo, S. S.,Ghorpade D. S., Modi, A. J. In Vitro antimicrobial activity of the crude extracts of Colocasia esculenta leaves L (Araceae). International Journal of Pharmaceutical Science and Research.1 (8), (2010). 
[17] Brown, A.C.,Reitzenstein, J. E., Liu, J.,Jadus, M. R. The anticancer effects of poi (Colocasiaesculenta) on colonic adenocarcinoma cells In vitro. Phytotherapy Research. 19(9), 767-771 (2005).

[18] Patil, B.R., Ageely, H. M. Anti lipidperoxidative activity of Colocasia esculenta leaf juice against CCL4 and Acetaminophen mediated cell damage. International Journal of Pharmaceutical Applications. 2 (3), 141-149 (2011).

[19] Namrata, B. S., Kumar, L., Dwivedi, S. C. Antibacterial and Antifungal Activity of Colocasia esculenta Aqueous Extract: An Edible Plant. Journal of Pharmacy Research 4(5), 14591460 (2011).

[20] Kumawat, N. S., Chaudhari, S. P., Wani, N. S., Deshmukh, T. A., Patil, V. R.Antidiabetic activity of ethanol extract of
Colocasia esculentaleaves in alloxan induced diabetic rats. International Journal of Pharm Tech Research.2 (2), 12461249 (2010).

[21] Kim, K. H., Moon, E.,Kim, S. Y.,Lee, K. R. Anti-melanogenic Fatty Acid Derivatives from the Tuber-barksof Colocasia antiquorum var. Esculenta. Bull. Korean Chem. Soc. 31(7), 2051 (2010).

[22] Kalariya, M., Parmar, S., Sheth,N. Neuro pharmacological activity of hydroalcoholic extract of leaves of Colocasia esculenta. Pharmaceutical Biology.48 (11), 1207-1212 (2010).

[23] Eddy, N. O. Inhibitive and adsorption properties of ethanol extract of Colocasia esculenta leaves for the corrosion of mild steel in H2SO4. International Journal of Physical Sciences. 4 (4), 165-171 (2009). 